\title{
Comparison of two Jacuzzis and Swimming Mild Recoveries on Heart Beat Rate and Myocardial Oxygen Consumption of swimming
}

\author{
Ensiyeh Aminian \\ Young Researchers and Elite Club, Torbat-e-heydarieh Branch, Islamic Azad University, \\ Torbat-e-heydarieh, Iran \\ E.Aminian77@yahoo.com
}

\begin{abstract}
Main aim of this research was comparing effect of two Jacuzzis, swimming mild recoveries on heart beat rate, and myocardial oxygen cost of swimming. Initially normal data distribution Kolmogorov Smirnov test was used in order to reflect the normal distribution of data. For data analysis descriptive statistics were used (placebo, median, mean, variance, and standard deviation) in order to compare changes of Lactic acid of heart rate beat and consumption oxygen of myocardial. Therefore, we used t student, alpha error is 0.05, and Excel 2007 and SPSS 18 did analysis. Result of research indicated that inactive recovery was effective on faster excreted lactic acid. Moreover, results of research indicated that recovery on mild swim Jacuzzi was effective on heart rate, myocardial consumption of oxygen. In addition, results of research indicated that heart rate and myocardial consumption of oxygen reduce in Jacuzzi recovery.
\end{abstract}

Key words: Myocardial Oxygen Consumption, Heart Beat Rate, Mild Swimming, Jacuzzi Recovery

\section{Introduction}

he hagfish is at one end of a spectrum of $\mathrm{T}$ vertebrate cardiac energy demands (Driedzic et al. 1987). The heart operates with the lowest after load of any vertebrate animal (Davie et al. 1987; Forster et al. 1988; Forster, 1989). There is no coronary blood supply. Even at maximal cardiac output, the mean circulation time must exceed $5 \mathrm{~min}$, as the circulating blood volume is high (Forster et al. 1989).

Following exercise, oxygen tensions in venous blood are low $(\mathrm{PvO} 20.47 \pm 0.2 \mathrm{kPa}$, Wells et al. 1986) and rise only slowly on recovery. This information suggests that after periods of swimming the hagfish myocardium must be capable of extracting oxygen at extremely low partial pressures or of functioning anaerobically or a combination of the two. By contrast, experimental evidence indicates that the hearts of teleost fish function aerobically (Driedzic, 1983; Driedzic et al. 1983: Farrellefa, 1985).

The anoxic tolerance of the heart of the Atlantic hagfish Myxine glutinosa has been demonstrated in vitro (Rybak and Boivinet, 1959), together with its dependence upon glycolysis for the supply of energy (Rybak, 1959; Hansen and Sidell, 1983). Recently it has been shown that M. glutinosa can maintain cardiac output in vivo 
even during severe environmental hypoxia (Axelsson et al. 1990).

This paper provides the first measurements of myocardial oxygen consumption in a hagfish Eptatretus cirrhatus at known work rates, and quantifies the substantial contribution of anaerobic metabolism to cardiac pumping under hypoxic conditions.

Heart Rate:

Resting heart rate is associated with cardiovascular and all-cause mortality, and the mortality benefit of some cardiovascular drugs seems to be related in part to their heart ratelowering effects. Since it is difficult to separate the benefit of heart rate lowering from other actions with currently available drugs, a 'pure' heart rate-lowering drug would be of great interest in establishing the benefit of heart rate reduction per se.

Heart rate is determined by spontaneous electrical pacemaker activity in the sinoatrial node. Cardiac pacemaker cells generate the spontaneous slow diastolic depolarisation that drives the membrane voltage away from a hyperpolarised level towards the threshold level for initiating a subsequent action potential, generating rhythmic action potentials that propagate through the heart and trigger myocardial contraction. If current is an ionic current that determines the slope of the diastolic depolarisation, which in turn controls the heartbeating rate. Ivabradine is the first specific heart rate-lowering agent to have completed clinical development for stable angina pectoris. Ivabradine specifically blocks cardiac pacemaker cell f-channels by entering and binding to a site in the channel pore from the intracellular side. Ivabradine is selective for the If current and exerts significant inhibition of this current and heart rate reduction at concentrations that do not affect other cardiac ionic currents. This activity translates into specific heart rate reduction, which reduces myocardial oxygen demand and simultaneously improves oxygen supply, by prolonging diastole and thus allowing increased coronary flow and myocardial perfusion. Ivabradine lowers heart rate without any negative inotropic or lusitropic effect, thus preserving ventricular contractility. Ivabradine was shown to reduce resting heart rate without modifying any major electrophysiological parameters not related to heart rate. In patients with left ventricular dysfunction, ivabradine reduced resting heart rate without altering myocardial contractility. Thus, pure heart rate lowering can be achieved in the clinic as a result of specific and selective If current inhibition.

\section{Recovery of Heart Rate}

After achieving peak workload, all the patients spent at least two minutes in a cool-down period during treadmill testing at a speed of $2.4 \mathrm{~km}(1.5$ mi) per hour and a grade of 2.5 percent. This period was considered the recovery period. The value for the recovery of heart rate was defined as the reduction in the heart rate from the rate at peak exercise to the rate one minute after the cessation of exercise.

We determined an abnormal value for the recovery of heart rate by finding the maximal value for the log-rank chi-square test statistic for all possible cutoff points between the 10th and 90th percentiles for the study cohort. A secondary abnormal value was based on the value for the 10th percentile for the study cohort. Today, using some biomechanical, physiologic, Nutritional and psychological are effective on achieving athletes to peak of their abilities. In each year, numerous researches do based on structure and do production systems of energy in athletes. One of sport, which has specific features and different techniques, is swimming. This exercise is different from other sports in which athletes from a standing vertical to horizontal and water always keep swimmer in specific condition, Objective of exercise is improving sports skill and general efficiency of body and it is important for athletics. Since, every day new records in various fields will be left in the global race for professional athletes and it provides strong incentive which increase on volume and intensity of training. These athletes use from the most intense workouts in order to increase ability of exercise. Although, amount of experience is important stimulus in order to improve health condition of athletes, but amount of experience is higher than recovery period, it can have some disadvantages like chronic fatigue and overtraining syndrome and finally it can have negative effect on kills and human ability of athletes. Principally, during exercise the muscle cells are stimulated and then deteriorated. 
Objective of research:

Main aim of this research is investigating relationship between heart rate in Jacuzzi recovery, consumption myocardial oxygen, and mild recovery swimming

Lactic acid: The final products of anaerobic energy that is caused by lack of oxygen

Operational definition: Blood lactate levels in the recovery period after mild swim in Jacuzzi throughout lactate meter and by middle finger

\section{Recovery:}

A period, which take from end of exercise to initial conditions or resting. Some effective factors on recovery are as following: Age, experience of athletes, environmental factors, internal factors, injury, food and Athlete's fitness level.

Operational definition:

Recovery included of recovery by mild swim 5 minutes and recovery in Jacuzzi

\section{Heart beat rate:}

Wave of contraction of the heart to start beating atrial sinus node starts and after adjustment, is running at about 60 to 70 beats per minute.

\section{Myocardial oxygen consumption:}

Mussels of heart called myocardial. Consumption of myocardial oxygen is determined by mechanical interaction between several factors. The most important of expansion and contraction of myocardial stress and heart rate variability. By increasing each factor in exercise, blood flow of myocardial increase in order to sending oxygen to myocardium.

Multiplied by the peak systolic blood pressure and heart rate are measured and it has significant relationship with consumption of oxygen in coronary blood flow in healthy people.

\section{Mild swim:}

Swimming breaststroke swimmer to swim easily with minimal pressure.

\section{Measuring heart beat:}

The best place to measure heart rate, wrist (carpal artery), neck (carotid artery), confusing at times (sometimes confused artery) or left side of the chest in order to ensure a consistent day-today measurement of heart rate is always in the morning before getting out of bed.

\section{Methodology:}

Initially normal data distribution Kolmogorov Smirnov test was used in order to reflect the normal distribution of data. For data analysis descriptive statistics were used (placebo, median, mean, variance, and standard deviation) in order to compare changes of Lactic acid of heart rate beat and consumption oxygen of myocardial. Therefore, we used $\mathrm{t}$ student, alpha error is 0.05, and Excel 2007 and SPSS 18 did analysis.

H1: significant relationship exists between heart rate and Jacuzzi recovery and mild swimming H2: significant relationship exist between myocardial consumption of oxygen in Jacuzzi recovery and mild swim

\section{Results:}

Table 1: Index of heart beat rate in two groups of Jacuzzi recovery and mild swim

\begin{tabular}{|c|c|c|c|c|c|}
\hline \multirow{2}{*}{ Recovery } & \multirow{2}{*}{$\begin{array}{c}\text { Num } \\
\text { bers }\end{array}$} & \multicolumn{2}{|c|}{ After swimming $200 \mathrm{~m}$} & \multicolumn{2}{|c|}{ After recovery } \\
\cline { 3 - 6 } & 14 & Mean & Sd & Mean & Sd \\
\hline $\begin{array}{c}\text { Jacuzzi } \\
\text { recovery }\end{array}$ & 180.42 & 1.55 & 98.07 & 1.1 \\
\hline Mild swim & 14 & 180.28 & 1.89 & 124.92 & 1.9 \\
\hline
\end{tabular}

Table 2: Index of myocardial consumption of oxygen in two groups of Jacuzzi recovery and mild swim

\begin{tabular}{|c|c|c|c|c|c|}
\hline \multirow{2}{*}{ Recovery } & \multirow{2}{*}{$\begin{array}{c}\text { Num } \\
\text { bers }\end{array}$} & \multicolumn{2}{|c|}{ After swimming $200 \mathrm{~m}$} & \multicolumn{2}{|c|}{ After recovery } \\
\cline { 3 - 6 } & 14 & Mean & Sd & Mean & Sd \\
\hline Jacuzzi & 180.42 & 1.55 & 98.07 & 1.1 \\
\hline recovery & & & & & 124.92 \\
\hline
\end{tabular}


Table 3: Difference between mean of heart beat rate in Jacuzzi recovery and mild swim

\begin{tabular}{|c|c|c|c|c|c|c|c|}
\hline \multicolumn{2}{|c|}{ Variables } & $\begin{array}{c}\text { Numb } \\
\text { ers }\end{array}$ & Mean & Sd & T & Sig & Results \\
\cline { 1 - 6 } $\begin{array}{c}\text { Heart } \\
\text { rate }\end{array}$ & Macuzzi & 14 & 82.35 & 2.1 & \multirow{2}{*}{63.39} & 0.001 & Approved \\
\cline { 2 - 8 } & Mild swimming & 14 & 55.35 & 2.1 &
\end{tabular}

Table 4: Difference between mean myocardial oxygen consumption in Jacuzzi recovery and mild swim

\begin{tabular}{|c|c|c|c|c|c|c|c|}
\hline \multicolumn{2}{|c|}{ Variables } & Numbers & Mean & $\mathrm{Sd}$ & $\mathrm{T}$ & Sig & Results \\
\hline \multirow{2}{*}{$\begin{array}{c}\text { Myocardial } \\
\text { consumption of } \\
\text { oxygen }\end{array}$} & Jacuzzi & 14 & 1424.18 & 58.1 & \multirow[b]{2}{*}{21.31} & \multirow[b]{2}{*}{0.001} & \multirow[b]{2}{*}{ Approved } \\
\hline & $\begin{array}{c}\text { Mild } \\
\text { swimming }\end{array}$ & 14 & 1122.07 & 49.4 & & & \\
\hline
\end{tabular}

Based on the table, $\mathrm{t}$ is 63.39 and sig in heart beat rate in Jacuzzi recovery and mild swim is $\operatorname{sig}=0.001$. Due $t$ sig is less than 0.05 , therefore, null hypothesis is rejected and it shows that significant relationship exists between heart rate and Jacuzzi recovery and mild swimming. In other words, with confidence of $95 \%$ there is significant relationship between swimming 200 $\mathrm{m}$ after recovery and Jacuzzi recovery and mild swim. Eventually, Jacuzzi recovery has more effect on heart beat rate of swimmers in comparison with recovery of mild swim.

In according to tale 2, $\mathrm{t}$ is 21.13 and significant of myocardial consumption of oxygen in Jacuzzi recovery and mild swim is 0.001 . As result of sig is less than 0.05, therefore, null hypothesis is rejected. In can be said that significant relationship exists between myocardial consumption of oxygen and it shows that Jacuzzi recovery is effective on myocardial consumption of oxygen.

In other words, Jacuzzi recovery has more effect on myocardial consumption of oxygen in comparison with mild swim recovery. Thus, second hypothesis "significant relationship exist between myocardial consumption of oxygen in Jacuzzi recovery and mild swim" is approved.

\section{Conclusion and Discussion}

Based on first hypothesis "significant relationship exists between heart rate and Jacuzzi recovery and mild swimming' results of research's Ramzan Pour et al (2010) who compared three methods of come back to initial ( mild swim, sitting and massage) on heart rate and lactate of blood in swimmers and they concluded that there is significant impact of massage on heart rate and they recommended that athletes use passive recovery in order to come back initial of heart rate. Ramzani et al 2003 compared effect of two types of active recovery (swimming in two conditions) and one type of inactive recovery (sitting) on changes of lactic and heart rate off swimmers. Results indicated that in order to come back to initial position, inactive recovery is better than active in order to reduce heart rate. Nick Dropper et al (2006), in their research about role of active and inactive recovery on lactate concentration and clinical heart and results indicated that heart rate in inactive recovery will reduce. In addition, our research is consistent with research of Nemati, (2005), Rashidi et al (2010), Kashef (2002) Kornelson et al (2010) Hara et al (1992), MacDonald et al (1999), MacDonald et al (2000). In according results of second hypothesis " significant relationship exist between myocardial consumption of oxygen in Jacuzzi recovery and mild swim " Mohebi et al (2009), investigated effect of intensity and amount of exercise on blood pressure and myocardial consumption oxygen and concluded that amount of exercise amount of exercise is not effective on consumption of oxygen. Results of our research is consistent with results of MacDonald et al (2000), Forjaz et al (2004) and it was inconsistent with results of Rezk et al (2006) who believed that intensity of exercise is not effective on blood pressure, heart rate, myocardial consumtion of 
oxygen.

Finally, it can be concluded that inactive recovery is effective on faster excreted lactic acid. Moreover, results of research indicated that recovery on mild swim Jacuzzi is effective on heart rate, myocardial consumption of oxygen. In addition, results of research indicated that heart rate and myocardial consumption of oxygen reduce in Jacuzzi recovery.

\section{References}

AXELSSON, M., FARRELL, A. P. AND NILSSON, S., Effect of hypoxia on the cardiovascular dynamics of the Atlantic hagfish, Myxine glutinosa. J. exp. Biol. 151, 297-316. 1990

DAVLE, P. S., FORSTER, M. E., DAVISON, W. ANDSATCHELL, G. H, Cardiac function in the New Zealand hagfish, Eptatretus cirrhatus. Physiol. Zool. 60, 233-240.1987

DRIEDZIC, W. R, The fish heart as a model system for the study of myoglobin. Comp. Biochem. Physiol. 76A, 487-493.1983

DRIEDZIC, W. R., SCOTT, D. L. AND FARRELL, A. P.. Aerobic and anaerobic contributions to energy metabolism in perfused isolated sea raven (Hemitripterus americanus) hearts. Can. J. Zool. 61,1880-1883.1983

DRIEDZIC, W. R., SIDELL, B. D., STOWE, D. AND BRANSCOMBE, R. (1987).

HANSEN, C. A. AND SIDELL, B. D, Atlantic hagfish cardiac muscle: metabolic basis of tolerance to anoxia. Am. J. Physiol. 244, R356R362. 1983

FARRELL, A. P., WOOD, S., HART, T. AND DRIEDZIC, W. R, Myocardial oxygen consumption in the sea raven, Hemitripterus americanus: the effects of volume loading, pressure loading and progessive hypoxia. J. exp. Biol. 117, 237-250.1985

FORSTER, M. E. Performance of the heart of the hagfish, Eptatretus cirrhatus. Fish Physiol. Biochem. 6, 327-331. 1989

Kashef, Majid, effect of intensity human activity in active recovery and inactive recovery on blood pressure and heart beat in young athletes, Shahid Rajaei University, 2002

MacDonald J, MacDougall J, Hogben C. The effects of exercise intensity on post exercise hypotension. J Hum Hypertens 13: 527531. 1999.

MacDonald JR, Hogben CD, Tarnopolsky MA, Mac- Dougall JD. Post exercise hypotension is sustained during mild exercise and simulated activities of daily living. J Hum Hypertens 15: 567 572. 2001

Ramzani, Alireza, Nikbakht, Hojatallah., Amir Tash, Ali Mohammad, effect of active recovery and inactive recovery methods on lactic acid of blood and hear beat rate after intensity activity in swimmers, Olympic journal. 2003

Ramezani Pour, Mohammad Reza., Rashid, Amir., Hassari, Mohsen, Comparing effect of three methods of come back to initial condition( mild swim, sitting, massage) on heart beat rate and lactate blood of young swimmers, Journal of Environmental Science \& Motion, Number 4: 37-46, 2010

Rashidi, Mohammad, Rashidi Pour, Ali, Ghorbani, Raheb, investigate effect of active recovery and inactive recovery on amount of lactic acid of blood in male athletes after intensity activities, Medical science journal of Semnan University, Fourth volume:34-46, 2010

RYBAK, B. Inhibition et restauration des contractions automatiques $\mathrm{du}$ myocarde branchial isol6 de Myxine glutinosa L. /. Physiol., Paris 51, 631-637.1959

Hara, H, and et al. Difference of physiological responses to swimming and ranning. Ann. Physiol.anthropol, 11(3) 9. 1992

RYBAK, B. AND BOIVINET, Caracteres biochimiques du coeur branchial de Myxine glutinosa. C. R. hebd. Sdanc. Acad. Sci. Paris, D 249, 2231-2 